\section{Speaking different languages on biodiversity}

SIR - Interdisciplinary conferences such as BioEcon (Biodiversity and Economics for Conservation), whose eighth meeting "Economic Analysis of Ecology and Biodiversity" has just finished, provide much-needed forums to cultivate the scientific collaborations on which mutual understanding depends. Economic context, in particular, is essential for understanding and reducing the ongoing pressures on biodiversity, as well as for developing successful, cost-effective and equitable conservation actions.

As conservation biologists at BioEcon, we were not expecting to be familiar with the intricacies of economic models. But we had failed to anticipate the differences in vocabulary in what we presumed to be common ground between our disciplines. Presentations on 'agricultural biodiversity', for example, turned out to be about crop and livestock genetic diversity, rather than, as conservation biologists would expect, on the diversity of wildlife associated with agricultural fields. In another example, the term 'statistical dichotomy' was used in place of our familiar 'binary variables'.

We were thus amused to read in "100 years ago" (Nature 442, 989; 2006) an accurate description of communication difficulties between scientific disciplines: "progress is not a little hampered by the fact that chemists and physicists cannot wander through the museums of nature in complete sympathy with one another... a confusion of language has arisen which keeps us apart". The world's threatened biodiversity cannot wait another 100 years for biologists and economists to overcome their language barriers.

R. M. Ewers ${ }^{\star} \uparrow$, A. S. L. Rodrigues $\uparrow$

*Institute of Zoology, Zoological Society of London, Regent's Park, London NW1 4RY, UK †Conservation Science Group, Department of Zoology, University of Cambridge, Cambridge CB2 3EJ, UK

\section{Bench-to-bedside solution to funding problems}

SIR - Recent budget allocations by the US National Institutes of Health (NIH) have aroused serious concern among researchers (see, for example, A. R. Marks J. Clin. Invest. 116, 844; 2006). The problem seems to stem from the division between those who are funded by the NIH and those who direct it. A great proportion of the former are doctors of research, whereas many of the latter are doctors of medicine. As its website shows, every director of the organization has held an MD degree. Unlike those seeking grants, only
4 out of 14 current advisory-committee members hold a PhD (see links from www. nih.gov/about/director/index.htm). Hence, disagreement is not surprising during a funding freeze.

This problem could, in part, be overcome by bridging the gap between medical and $\mathrm{PhD}$ students - a gap that is already narrowing, as noted in your News Feature "Them and us no longer" (Nature 439, 779-780; 2006). The emergence of 'bench-tobedside' interdisciplinary research requires and promotes mutual understanding between physicians and scientists.

Yet the road ahead seems long, and many prejudices still exist. It is crucial to introduce new programmes aimed at acclimatizing medical students to the research process and $\mathrm{PhD}$ students to clinical practice. As a graduate student, I find this lacking in most institutions. The exception is a limited MD$\mathrm{PhD}$ programme, only available to a handful of students. This concept should be expanded into an integral part of medical education, one that allows for greater understanding and interaction between graduate students and medical students.

\section{Samuel F. Bakhoum}

Molecular and cellular biology programme, Dartmouth Medical School, Hanover, New Hampshire 03755, USA

\section{Learning from painful experience of disaster}

SIR - Your Editorial about preparing for natural disasters ("State of readiness" Nature 442, 847-848; 2006) provides some good advice. As someone whose lab was out of commission for two years after the Northridge earthquake of 1994, I would like to suggest some more precautions, and lessons learned, that might be helpful to other readers.

First and most important, have at least two sets of all important data, one kept in the lab and the other at the home of the project director. It is best to have both electronic and paper copies of all important data. All expensive equipment should be kept off the floor, if possible, to avoid ground-water damage and should be covered with plastic sheeting when not in use to avoid damage from water coming through the ceiling. Expensive equipment should be secured so that it will not fall off counters - but security devices should be easily removable in case items have to be moved quickly. Finally, chemicals should be stored where they can not easily be jostled to the floor, using cabinet locks and shelf lips. These few tips could help save your lab in the event of a disaster. Steven B. Oppenheimer

Center for Cancer and Developmental Biology, California State University Northridge, Northridge, California 91330-8303, USA

\section{Hoyle's observations were right on the ball}

SIR - In his In Retrospect article "Out of the darkness" (Nature 442, 986; 2006), Jay M. Pasachoff notes the impact of Fred Hoyle's novel The Black Cloud (first published in 1957) and its contemporary relevance. We would like to add a further aspect: the contribution of two ideas in Hoyle's book to vision research and to our understanding of the perceptual guidance of action.

The characters in the book discover an ominous black cloud that appears to be heading towards Earth. Will the cloud hit Earth and, if so, when? The first question is solved when the characters examine the relative speed at which the cloud is translating across the night sky to the rate at which it is looming, or seeming to get larger. The second question is tackled with a bit of impromptu algebra in which the time until impact is calculated from the ratio of the current size of the cloud to its rate of change. A mathematical derivation of the formula is provided.

A footballer wishing to head an approaching ball needs to know where the ball is going relative to the head, and when it will hit or pass the head. The player could estimate the trajectory of the ball from knowledge of its position and velocity. However, David Lee realized in the 1970s that the brain can use the ratio of size to its rate of change, previously identified by Hoyle, to estimate the imminence of arrival. David Regan realized soon afterwards that the brain can use the ratio of lateral speed to looming rate to calculate where an object is travelling. These elegant solutions bypass the need to know position and velocity, so that the two quantities of interest can be estimated directly. This human ability is important for the characters in Hoyle's story because the position and velocity of the cloud are unknown.

An ability to estimate these quantities is of use not just for heading a ball, but also when trying to cross a street full of cars, return a tennis serve or pick up a cup of coffee while rushing past your desk. Since the early work of Lee and Regan, a considerable amount of research in areas including psychophysics, motor action, neurophysiology and computational modelling has followed (see D. Regan and R. Gray Trends in Cognitive Sciences 4, 99-107; 2000). The whole body of work that exists today can be traced back to a casual footnote and a couple of sketches in a science-fiction novel.

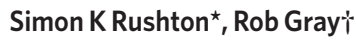

*School of Psychology, Cardiff University, Tower Building, Park Place, Cardiff CF10 3AT, UK $\dagger$ Department of Applied Psychology, Arizona State University, 7001 E Williams Field Road, 340J Sutton, Mesa, Arizona 85212, USA 